\title{
Mapeamento de Rádios Comunitárias na Amazônia como ferramenta ao Desenvolvimento Sustentável ${ }^{1}$
}

\author{
Mapping of Community Radios in the Amazon as a \\ Tool for Sustainable Development
}

\begin{abstract}
Rosane Albino Steinbrenner | Universidade Federal do Pará (UFPA)
Professora Adjunta da Universidade Federal do Pará (UFPA). Possui especialização em Gestão Pública, Planejamento e Meio Ambiente (2004), mestrado em Planejamento do Desenvolvimento (2006) e doutorado em Desenvolvimento Socioambiental (2011) pelo Programa de Pós-Graduação do Núcleo de Altos Estudos Amazônicos da Universidade Federal do Pará (NAEA/UFPA). Pesquisa fenômenos de Comunicação Comunitária em regiões periféricas. É professora colaboradora do Programa de Pós-Graduação em Comunicação Cultura e Amazônia (PPGCOM-UFPA). Email: nani.steinbrenner@gmail.com
\end{abstract}

\begin{abstract}
Resumo
O presente artigo apresenta os principais resultados do projeto de pesquisa "Mídia Cidadá e Desenvolvimento Sustentável: mapeamento e análise de rádios comunitárias em áreas de pressão socioambiental na Amazônia", que busca entender a dimensão e o papel potencial das rádios comunitárias nos embates discursivos pelo desenvolvimento da região amazônica. $\mathrm{O}$ objeto da investigação são rádios comunitárias situadas em áreas de potencial conflito socioambiental na Amazônia Legal, o que inclui disputas por território ou pelo uso de recursos naturais, considerando-se grandes obras de impacto, mas também Unidades de Conservação e Terras Indígenas nos nove estados da região. Como produto central do projeto foi gerada uma cartografia digital sobre comunicaçáo cidadã e desenvolvimento sustentável na regiâo, na perspectiva de gerar insumos para o fortalecimento da comunicaçáo comunitária como espaço de contra-hegemonia midiática e consequente empoderamento de grupos locais nas decisóes que afetem seu bem-estar.
\end{abstract}

Palabras Claves: Desenvolvimento sustentável, rádios comunitárias, mapa digital.

\begin{abstract}
This article presents the main results of the research project entitled "Citizen Media and Sustainable Development: Mapping and analysis of community radios in areas of social and environmental pressure in the Amazon Region". The project seeks to understand the significance and the potential role of community radios in the discursive arena about the development of the Amazon region. The research objects are community radio stations located in potential environmental and social conflict areas in the Amazon, including disputes over territory or the use of natural resources, considering the significant (state) projects of impact, but also Conservation Units and Indigenous Lands in nine states in the region. The main product of the project was a digital cartography about citizen communication and sustainable development in the region, able to generate inputs for the strengthening of community communication as a space for alternative media and empowerment of local groups in decisions that affect their well-being.
\end{abstract}

Keywords: Sustainable development, community radios, digital map. 


\section{Introdução}

O presente artigo apresenta os principais resultados quantitativos do projeto de pesquisa intitulado "Mídia Cidadã e Desenvolvimento Sustentável: mapeamento e análise de rádios comunitárias em áreas de pressão socioambiental na Amazônia" ${ }^{2}$. O projeto buscou entender, por meio do mapeamento de emissoras comunitárias licenciadas, a dimensão e o papel potencial das rádios comunitárias nos embates discursivos pelo desenvolvimento da regiáo amazônica. $\mathrm{O}$ objeto da investigação são rádios comunitárias situadas em áreas de potencial conflito socioambiental na Amazônia Legal, o que inclui disputas por território ou pelo uso de recursos naturais, considerando-se grandes obras de impacto (em especial hidrelétricas pelo contexto e circunstâncias atuais) mas também Áreas de Proteção (com foco especial sobre Terras Indígenas, grupos de histórica invisibilidade) nos nove estados da região - Acre, Amapá, Amazonas, Pará, Rondônia, Roraima, Tocantins, mais o estado do Mato Grosso e parte do Maranhão (a Oeste do Meridiano 44). Foram mapeadas ao todo 504 rádios comunitárias licenciadas pelo Ministério das Comunicações (MINICOM, 2015) em 436 municípios amazônicos. Optou-se pela seleção das rádios comunitárias licenciadas - Licença Definitiva (LDE) e Licença Provisória (LPE) -, na medida em que estas emissoras, já tendo vencido todas as etapas do processo de legalização, por vezes longo e frustrante, já deteriam, pressupõe-se, as condiçôes jurídicas, técnicas e administrativas para estarem em funcionamento e, portanto, seriam potencialmente capazes de atuarem no campo midiático e se inserirem no campo do desenvolvimento de suas localidades.

A meta principal do projeto foi gerar uma cartografia digital que apresentasse uma interface possível entre comunicação cidadã e desenvolvimento sustentável na região, na perspectiva de gerar insumos para o fortalecimento da comunicação comunitária como espaço de resistência midiática e consequente empoderamento de grupos locais nas decisôes que afetem seu bem-estar. Também por meio das informaçôes geradas e cenários revelados, busca favorecer políticas públicas ou ações que fortaleçam os meios comunitários e o protagonismo local nos embates discursivos que decorrem do modelo de desenvolvimento para a regiáo amazônica. Uma região megadiversa, biológica e etnicamente falando, território singular duplamente periférico por seus baixos indicadores sociais e pelo histórico isolamento, explorada historicamente a partir de uma visão exógena, movida por interesses externos, nacionais e internacionais.

\section{O mapa digital}

O mapa digital das rádios comunitárias gerado pela pesquisa e disponível na internet, apresenta, numa perspectiva socioambiental, o dimensionamento das potencialidades das rádios comunitárias em relação ao desenvolvimento sustentável da região. Esse dimensionamento é construído por meio do cruzamento de dados, por município: cruza-se 
a localização das rádios comunitárias licenciadas pelo então Ministério das Comunicações (MINICOM, 2015) com duas variáveis reconhecidamente essenciais à conformação e preservação da megadiversidade étnica e ambiental da região - as Unidades de Conservação (UCs) (SNUC/ MME, 2015), incluindo seus dois tipos de uso, sustentável e de proteção integral, e as Terras Indígenas (TIs) (FUNAI, 2015), decretadas, homologadas e em estudo. Como terceira variável, o mapa inclui também as Usinas Hidrelétricas (UHEs) que fazem parte do Projeto de Aceleração do Crescimento (PAC, 2015) - em funcionamento, em construção ou já previstas nos rios da Bacia Amazônica -, todas elas obras consideradas de alto impacto socioambiental na região.

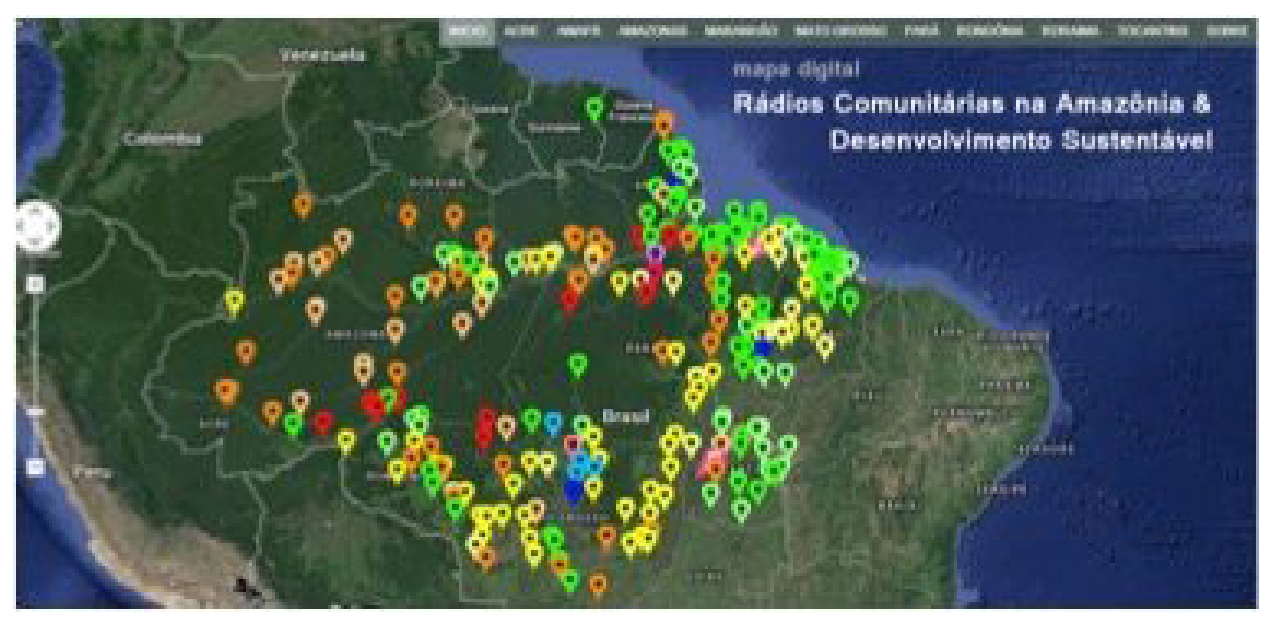

Figura 1: Mapa Digital de Rádios Comunitárias na Amazônia e Desenvolvimento Sustentável

Um mapa digital ou cartografia digital permite uma visualização dinâmica dos dados da pesquisa e consiste em uma imagem virtual que apresenta um grande conjunto de informaçóes com base georreferenciada (longitude/latitude). Optou-se pelo chamado mapa inteligente, que se diferencia por abrigar informaçóes atualizadas e detalhadas, que contribuem para facilitar e melhorar planejamentos e açóes. O mapeamento digital foi realizado utilizando softwares livres de georreferenciamento com gerenciador de conteúdo web Wordpress juntamente com o tema "Mapas de vista”, permitindo a visualização dinâmica dos dados da pesquisa ${ }^{3}$.

\section{Conceitos centrais}

A noção de sustentabilidade considerada vincula-se à ideia mais ampla e complexa do equilíbrio duradouro entre a humanidade e o seu ambiente, que se integra à noção de um desenvolvimento sustentável em sua perspectiva multimensional, ou seja, o qual em sua formulação busca integrar várias dimensóes - a ambiental e econômica, mas também a social e a cultural. Tal noção, mais integral de sustentabilidade se acha pautada desde a I Conferência do Meio Ambiente, em Estocolmo, em 1972, quando foi criado o Programa das Naçóes Unidas para o Meio Ambiente (PNUMA). Naquele momento a 
noção de sustentabilidade já trazia a ideia de complexidade e transversalidade, apresentadas especialmente no conceito de "ecodesenvolvimento" de Ignacy Sachs (2004), que apresentava a noçáo de sustentabilidade a partir do tripé da eficiência econômica, prudência ecológica e equidade social.

Foi a partir dessa noção mais integral que se originaram as bases e os esforços para a construção do conhecido Relatório Brundtland (1987), com a definição mais citada até hoje de desenvolvimento sustentável, concebido como "o desenvolvimento que satisfaz as necessidades presentes, sem comprometer a capacidade das gerações futuras de suprir suas próprias necessidades". Tal perspectiva diz respeito também ao local como palco central da territorialidade e à endogenia como vetor do desenvolvimento, isto é, pressupóe o protagonismo dos atores locais como fator central na construção de um desenvolvimento humano local sustentável.

Já a noção de mídia cidadã é entendida como o meio comunicativo que se origina e/ou desenvolve-se como um projeto político-cultural capaz de promover cidadania na comunidade onde atua, sendo assim capaz de gerar consciência política e mudanças sociais na sua comunidade, seja ela geográfica ou movida por afinidades. As rádios comunitárias, entendidas como emissoras que "têm gestáo pública, operam sem fins lucrativos e têm programaçáo plural" (PERUZZO,1999, p. 252-253), se inserem nesta perspectiva de mídias cidadãs, na medida em que são reconhecidas idealmente como meios de contra-poder, de expressão democrática e de pertencimento local (LEAL, 2007). Buscam, como afirma Peruzzo (2009) provocar a reinvenção de um modelo de comunicação de interesse público. Elas surgem da articulação dos movimentos sociais pela democratização da comunicação no anos de 1990, sendo regularizadas no final da década (Lei 9.612/98), com potencial estratégico na articulaçáo de novos arranjos institucionais e (re)posicionamentos de grupos sociais no campo da comunicação e assim, por conseguinte, no campo do desenvolvimento da regiáo.

A relação entre comunicação cidadã ou comunitária e desenvolvimento sustentável se dá num campo de permanente tensão, e que é, pode-se dizer, o prolongamento da tensão natural entre as noçóes de desenvolvimento e sustentabilidade, de naturezas regidas por lógicas opostas e, na prática, inconciliáveis. O cerne do problema é que o paradigma do desenvolvimento sustentável está baseado numa racionalidade econômica, não ecológica e não inclusiva, ou seja, as principais suposiçóes do paradigma econômico neoclássico permanecem intocadas e a ideia de desenvolvimento como progresso e crescimento econômico permanece inquestionável (FERNANDES, 2003). Nessa perspectiva, os processos de tomada de decisão sobre o uso de recursos naturais tende a considerar de forma exclusiva ou fortemente desigual os atores sociais (STEINBRENNER, 2011, p. 97).

Por sua complexidade de fatores, a relação comunicação e desenvolvimento deve ser pensada a partir de uma perspectiva interdisciplinar, que neste estudo tem como base a Teoria dos Campos Sociais, de Bourdieu (1986). Esta teoria se constitui, de forma ampla, numa sociologia do poder com alto teor 
explicativo do princípio da organização social em qualquer sociedade. $\mathrm{O}$ autor parte de uma visão topológica da sociedade, que seria formada por uma pluralidade de espaços relativamente autônomos, denominados "campos", entendidos como microcosmos dotados de sentido e regras próprias e capazes de definir modos específicos de dominação e, consequentemente, de resistência e reação. O campo em disputa sob foco central da pesquisa é de forma imediata o campo da comunicação, mais especificamente o sub-campo ou campo midiático, no qual as rádios comunitárias como meios alternativos se inserem, porém relacionado direta ou indiretamente ao campo do desenvolvimento - na medida em que se inserem como instrumento potencial de ampliação da esfera pública em territórios onde ocorrem processos de intervenção de alto impacto e, por conseguinte, constituindo um cenário de conflitos de interesse

\section{Território e variáveis da pesquisa - a Amazônia}

A Amazônia Legal, definida por critérios administrativos para fins de planejamento nos anos 1950 (Lei 1.806/53), e adotada como referência neste estudo, inclui os sete estados da regiáo Norte e mais o estado de Mato Grosso e parte do Maranhão (a oeste do Meridiano 44), com uma área total de 5,2 milhóes de quilômetros quadrados, o que representa cerca de $60 \%$ do território nacional, onde vive uma população aproximada de 22 milhóes de habitantes num total de 772 municípios (13,83\% do total dos municípios brasileiros) - 68,9\% residentes na área urbana, a maior parte residente em metrópoles e cidades médias, e $31,1 \%$ na área rural. Uma população altamente heterogênea étnica e culturalmente, que abrange ribeirinhos e centenas de grupos indígenas e de povoamentos quilombolas.

É considerada uma região heterogênea e megadiversa, o que significa dizer que abriga um volume de biodiversidade que é fundamental para todo o planeta. A floresta amazônica representa mais da metade das florestas tropicais úmidas do planeta, onde se concentram 54\% das espécies de plantas, $73 \%$ das de mamíferos e $80 \%$ das de aves existentes no território nacional. Possui ainda o rio mais extenso do mundo, o Amazonas, e a maior bacia hidrográfica do planeta, que contribui com $20 \%$ de toda a água doce que flui dos continentes para os oceanos (GEOAMAZÔNIA, 2012).

\section{Unidades de Conservação e Terras Indígenas}

A existência de Áreas Protegidas na Amazônia, que incluem Unidades de Conservação, Terras Indígenas e Territórios Quilombolas, são consideradas a principal ferramenta de preservaçáo de tamanha diversidade biológica, étnica e cultural da regiáo. O Sistema Nacional de Unidades de Conservação da Natureza (SNUC), que estabelece as normas para criação e gestão das Unidades de Conservação (UC) existentes no país, foi instituído no ano 2000, pela Lei 9.985. Em 2002, o governo federal criou o Programa de Áreas Protegidas da Amazônia (ARPA), que se insere no contexto da delimitaçáo de determinados espaços territoriais com seus respectivos recursos ambientais, aos quais devem ser destinados cuidados específicos de proteção da sua população tradicional 
e de seu patrimônio biológico, como a principal alternativa de conservação da natureza do país (VERÍSSIMO et al., 2011).

Originalmente, somente as UCs eram consideradas Áreas Protegidas, porém, a partir de 2006, o Plano Nacional de Áreas Protegidas (PNAP) incluiu neste conceito os Territórios Quilombolas e as Terras Indígenas (TI)

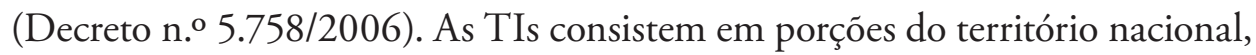
de propriedade da Uniáo, habitadas e de uso exclusivo de um ou mais povos indígenas, que as utilizam em suas atividades produtivas.

Estudos mostram que elas têm sido eficazes contra o desmatamento na Amazônia Legal (IMAZON), porém sofrem ameaças e pressôes diversas - a instalação de projetos de infraestrutura, em especial hidrelétricas e as invasóes e conflitos fundiários, que têm provocado iniciativas para reduzir ou retirar a proteção legal (desafetação) de Áreas de Proteção na região ${ }^{4}$. Evidencia-se, portanto, uma clara disputa e contradição entre duas grandes políticas, de um mesmo governo, ambas com foco sobre a região amazônica: a de proteção da biodiversidade e a de produção de energia. Setores estratégicos, nos quais as decisóes em geral carecem de transparência e debate público.

\section{Projeto hidrelétrico para a Amazônia}

Atualmente, são 23 grandes hidrelétricas que integram a lista dos Planos Decenais de Energia de 2020 a 2023 (13 delas constam da previsão atualizada do PAC, obras selecionadas neste estudo), projetos que em conjunto acenam com uma nova configuração ambiental, social e territorial para a região amazônica. Segundo diversos estudos, os impactos da construção de grandes hidrelétricas são muitos e já conhecidos, entre os quais, os ocasionados pelos impactos migratórios gerados pela atração direta de trabalhadores e indireta de pessoas em busca de oportunidades - que irão se sobrepor a "um quadro de alta precariedade no acesso a bens e serviços públicos (saúde, educação, saneamento, moradia, alimentação, entre outros) e de pressóes de diversas ordens sobre os recursos naturais" - e os impactos socioambientais causados pela interferência direta e indireta das obras em Unidades de Conservação, Terras Indígenas, Territórios Quilombolas.

Não existem cálculos do aumento populacional esperado diante do conjunto das hidrelétricas previstas até agora na Amazônia, assim como não existe qualquer estimativa dos impactos sociais e ambientais decorrentes do fluxo migratório (INESC, 2015). Belo Monte é o exemplo mais dramático dessa falta de planejamento. O município de Altamira, no Oeste do Pará, regiáo da Transamazônica - outra obra emblemática de alto impacto na região - e sede administrativa da obra, que em 2010 tinha cerca de 100 mil habitantes, viu sua população subir para mais de 150 mil.

Um dossiê publicado pelo Instituto Socioambiental (ISA, jun. 2015), mostra um cenário caótico em vários setores do município após o licenciamento da obra em 2011 e o início do processo de migração populacional. Tais denúncias, que vêm sendo apontadas por ONGs ambientalistas, encabeçadas pelo Movimento Xingu Vivo Para Sempre (MXVPS), agora também repercutem na mídia5. O governo, entretanto, ignora as denúncias, as críticas e os impactos já 
visíveis. Em contraponto, os investimentos no projeto hidrelétrico continuam sendo defendidos como estratégicos para a ampliação da geração de energia no país, com sua consequente importância para as dinâmicas econômicas.

É justamente esse debate público inclusivo, de todos os envolvidos e afetados pelas decisóes de planejamento - que não aconteceu em Belo Monte, onde não foram realizadas audiências públicas junto às populações indígenas atingidas -, que as rádios comunitárias, como meios comunitários, alternativos à grande mídia e tradicionalmente vinculados aos segmentos populares e originados dos movimentos sociais, podem vir a favorecer.

\section{As rádios comunitárias}

Muitos grupos e indivíduos em todo o mundo têm descoberto que o rádio lhes permite controlar uma ferramenta de comunicação genuína que fomenta a criatividade e facilita o acesso popular. Assim o rádio tem sido ao longo do tempo instrumento fortemente atrativo para a comunicação participativa e considerado o meio ideal por sua simplicidade - fácil acesso e baixo custo - para provocar mudanças sociais. Em cada regiáo elas recebem uma denominação diferente, segundo o contexto sociocultural e jurídico do país onde se localiza: rádio popular ou educativa na América Latina, rádio rural ou local na África, rádio pública na Austrália, rádio livre ou associativa na Europa e rádio comunitária no Brasil (STEINBRENNER, 2011).

Todos estes nomes descrevem o mesmo fenômeno: conseguir fazer-se ouvir e democratizar a comunicação na escala comunitária. Elas são reconhecidas, de forma geral e idealmente, como meios de contra-poder, de expressáo democrática e de pertencimento local, com vistas a provocar a reinvençáo de um modelo de comunicação de interesse público (PERUZZO, 2009).

Em termos quantitativos não há dúvidas de seu vigor. Em quase duas décadas, desde a aprovação da Lei da Radiodifusão Comunitária (Lei 9.612/98), o número de emissoras comunitárias FM, de baixa potência (até 25 wats) e reduzido alcance (1 km de raio), licenciadas pelo Ministério das Comunicaçóes, atual Ministério da Ciência, Tecnologia, Inovaçôes e Comunicaçôes (MCTIC), ultrapassa o de emissoras FM comerciais (MINICOM, 2014).

Tabela 1: Sistema de Radiodifusáo Sonora no Brasil (2014)

\begin{tabular}{|l|l|l|l|l|l|}
\hline & FM & OM & OC & OT & RADCOM \\
\hline Comercial & 2684 & 1766 & 65 & 72 & \\
\hline Educativa* & 525 & 15 & 1 & 2 & \\
\hline Radcom & & & & & 4641 \\
\hline Total & $\mathbf{3 2 0 9}$ & $\mathbf{1 7 8 1}$ & $\mathbf{6 6}$ & $\mathbf{7 4}$ & $\mathbf{4 6 4 1}$ \\
\hline Total Geral & $\mathbf{9 7 7 1}$ & \multicolumn{5}{|l|}{} \\
\hline
\end{tabular}

Elaborado pelo autor. Fonte: Dados gerais - (05.2014);

*Rádios Educativas (09.2014) - Ministério das Comunicações (MiniCom), SRD

http://www.mc.gov.br/espaco-do-radiodifusor 
Na Amazônia (Tabela 2), segundo dados do Ministério das Comunicações (2015), já foram outorgadas cerca de 570 emissoras comunitárias, sendo que 504 destas encontram-se licenciadas - de forma definitiva ou provisória - em mais da metade (56,4\%) dos 772 municípios dos nove estados que formam a Amazônia Legal. O número de rádios comunitárias representa pouco mais de $75 \%$ do total de emissoras comerciais na regiáo 7 . Se considerarmos que mais da metade destas emissoras comunitárias licenciadas, ou seja, 265 delas, não disputam audiência com rádios comerciais, pois são, segundo dados da Anatel (2015), a única emissora de rádio ou o único meio de comunicação massivo eletrônico em seus municípios - capazes, portanto, de produzir informação sobre a realidade local no meio mais popular que existe até hoje -, temos aí um cenário extremamente revelador do potencial estratégico da radiodifusão comunitária.

Tabela 2: Municípios da Amazônia Legal com Rádios Comunitárias licenciadas por Unidade da Federaçáo (ANATEL/SRD - Jun. 2015)

\begin{tabular}{|c|c|c|c|c|c|}
\hline $\begin{array}{l}\text { Unidade da } \\
\text { Federaçáo }\end{array}$ & $\begin{array}{c}\text { Total de } \\
\text { Municípios }\end{array}$ & $\begin{array}{c}\text { Total de } \\
\text { municípios } \\
\text { c/ Radcom }\end{array}$ & $\%$ & $\begin{array}{c}\text { Radcom } \\
\text { como única } \\
\text { emissora de } \\
\text { rádio local }\end{array}$ & $\begin{array}{l}\text { Radcom } \\
\text { como único } \\
\text { meio massivo } \\
\text { eletrônico }\end{array}$ \\
\hline AMAZONIA & 772 & 436 & 56,5 & 200 & 65 \\
\hline Acre & 22 & 5 & 22,7 & 0 & 0 \\
\hline Amapá & 16 & 14 & 87,5 & 5 & 0 \\
\hline Amazonas & 62 & 35 & 57,3 & 21 & 0 \\
\hline Pará & 144 & 95 & 65,9 & 25 & 15 \\
\hline Rondônia & 52 & 36 & 69,2 & 9 & 4 \\
\hline Roraima & 15 & 5 & 33,3 & 2 & 0 \\
\hline Tocantins & 139 & 68 & 48,9 & 45 & 25 \\
\hline Mato Grosso & 141 & 77 & 54,6 & 22 & 5 \\
\hline Maranhão* & 181 & 101 & 55,8 & 71 & 16 \\
\hline
\end{tabular}

Elaborado pelo autor. Fontes: IBGE - Cadastro de Municípios localizados na Amazônia Legal (2014); Ministério das Comunicaçóes (jun./2015); e Anatel - Sistema de Controle de Radiodifusão (SRD) - jun. 2015.

* Foram considerados os 181 municípios do Maranhão que integram a Amazônia Legal, localizados a Oeste do Meridiano 44 (83,4\% do total do Estado).

Os números, entretanto, apesar de expressivos e crescentes, em termos quantitativos estão longe de revelar a realidade do fenômeno das rádios comunitárias no Brasil. O número de rádios comunitárias de fato em atividade é impreciso e difuso em função da clandestinidade imposta a inúmeras emissoras que praticam o exercício temporário e arriscado da rádio livre, expostas à fiscalização e apreensão de seus equipamentos e, ainda hoje, à abertura de processos judiciais por parte da Anatel e da Polícia.

São muitas as pressôes enfrentadas pelas emissoras, tanto para se legalizarem quanto para se manterem no ar. As limitaçóes impostas pela Lei 9.612 - de alcance, potência e frequência, de associação e expansão por meio de rede, além 
do modelo limitado de gestão financeira, que permite apenas o "apoio cultural" restrito a apoiadores com sede na localidade - somados à extrema burocracia do processo de legalização das rádios comunitárias e à falta de políticas públicas, acabam por beneficiar as emissoras "apadrinhadas", seja por religiosos ou políticos, ou ainda aquelas que simplesmente reproduzem os modelos comerciais. Isso cria uma onda de emissoras "pseudo-comunitárias", que se constituem por interesse privado, reproduzem os formatos comerciais e não são abertas à participação da comunidade (STEINBRENNER, 2011).

A existência e funcionamento de emissoras comunitárias na Amazônia como espaços públicos de reação ou resistência no campo midiático de regióes periféricas ${ }^{8}$ como a Amazônia, se tende a ser ainda mais desafiador, somente se considerarmos a dimensão do território e a precariedade de infraestrutura na regiáo, poderia significar a possibilidade de atender à formulação de informaçôes e visões de mundo no interesse de grupos historicamente desconsiderados pelos atores politicamente influentes da esfera pública ${ }^{9}$, onde se reproduz, de forma ainda mais aguda, o padrão global de concentração dos meios de comunicação.

\section{Etapas da pesquisa e resultados}

O projeto de pesquisa "Mídia Cidadã e Desenvolvimento Sustentável: mapeamento e análise de rádios comunitárias em áreas de pressão socioambiental na Amazônia”, contou com duas etapas de coleta e análise de dados com metodologias distintas. A primeira etapa da investigação, de caráter mais quantitativo, consistiu na fase de mapeamento e identificação do cenário de pesquisa, na qual foram levantados e cruzados dados secundários de:

1) Emissoras comunitárias licenciadas pelo governo em municípios dos nove estados que formam a Amazônia Legal - Acre, Amapá, Amazonas, Mato Grosso, Pará, Tocantins, Rondônia, Roraima e parte do Maranhão (a Oeste do Meridiano, $44^{\circ} \mathrm{O}$ ), de acordo com dados secundários obtidos junto aos sites do Ministério das Comunicações (2015) e da Anatel (2015), conferidos por município na página do Sistema de Controle de Radiodifusão (SRD);

2) Demais meios massivos eletrônicos (rádios comerciais em Ondas Médias, Frequência Modulada, Ondas Curtas e Ondas Tropicais e Retransmissoras (RTV) e Repetidoras de TV (RPTV), existentes nos municípios amazônicos, também junto ao SRD (2015);

3) Unidades de Conservação (UCs) existentes, de acordo com o Ministério do Meio Ambiente (2015);

4) Terras Indígenas (TIs) criadas ou previstas, de acordo com dados do site da Funai (2015);

5) Usinas Hidrelétricas (UHEs) em obras, previstas e em funcionamento, conforme dados disponibilizados pelo site do Programa de Aceleração do Crescimento (PAC, 2014). 
Inicialmente o projeto previa a inclusão também de Territórios Quilombolas, incluídos recentemente (2006) na condição de Áreas Protegidas e que já chegam ao número impressionante de 856 áreas certificadas na Amazônia. Da mesma maneira, previa a inclusão de outras obras de alto impacto na região, além das usinas hidrelétricas, como rodovias ou projetos de mineração, porém tais dados não foram incluídos na análise da pesquisa e no mapa digital em função do volume total de dados em relação ao fator tempo do projeto, e principalmente pela situação de acirramento em torno do projeto hidrelétrico do governo para a regiáo, especialmente sinalizadas pelas obras de Belo Monte e do complexo do Tapajós, que afetam de forma especialmente brutal as populaçóes indígenas. Todavia, em função da característica dinâmica do mapeamento digital, também chamado de cartografia digital, é possível a inclusão permanente de novos dados e variáveis.

\section{Dados levantados e cenários revelados}

Segundo dados do Ministério das Comunicaçôes (2015), 504 rádios comunitárias estão licenciadas em mais da metade (57,5\%) dos 772 municípios dos nove estados que formam a Amazônia Legal, o que representa perto de 75\% do total de emissoras comerciais na regiáo. Se considerarmos que mais da metade destas emissoras comunitárias (52,5\%) na região, ou seja, 265 delas, não disputam audiência com rádios comerciais, pois são, segundo dados da Anatel (2015), a única emissora de rádio ou o único meio de comunicação eletrônica em seus municípios, capazes, portanto, de produzir informação sobre a realidade local no meio mais popular que existe até hoje, temos aí um cenário extremamente revelador do potencial estratégico da radiodifusão comunitária.

\section{Cruzando os dados: dimensões e potencialidades reveladas}

Das 504 rádios comunitárias licenciadas na Amazônia, cerca de 45\% delas estão localizadas em municípios que possuem em seus territórios Unidades de Conservação, num total de 296, distribuídas em maior número nos municípios do Pará (54), seguido do Maranhão (48) e do Amazonas (30). Em relação às Terras Indígenas, a partir do cruzamento de dados realizado pela pesquisa, verificou-se que um terço das rádios comunitárias (152) está licenciado em municípios que abrigam TIs, num total de 297 Terras Indígenas distribuídas em 135 municípios, praticamente a metade em municípios do Amazonas (149 TIs), seguido do Mato Grosso (87 TIs) e do Pará (69 TIs) ${ }^{10}$ (Tabela 3).

No que diz respeito às hidrelétricas na região, tomou-se como referência o balanço do PAC, de outubro de 2014, que aponta o número de 13 projetos de hidrelétricas para a Amazônia, todos eles situados ao menos em um município que abriga rádio comunitária. As UHEs encontravam-se em diferentes estágios: quatro em operação ${ }^{11}$, duas já concluídas ${ }^{12}$, cinco em obras ${ }^{13}$ e duas em fase de ação preparatória ${ }^{14}$. As UHEs previstas pelo PAC e consideradas no estudo abrangem 23 municípios e, destes, 17 possuem rádios comunitárias licenciadas. Destes municípios, pouco menos da metade, sete deles (42\%), abrigam também Terras Indígenas e Unidades de Conservação 
Tabela 3: Rádios Comunitárias licenciadas na Amazônia Legal por Unidade da Federaçáo localizadas em municípios com Usinas Hidrelétricas, Unidades de Conservaçáo, Terras Indígenas (2015

\begin{tabular}{|l|l|l|l|c|l|l|}
\hline $\begin{array}{c}\text { Unidade da } \\
\text { Federaçáo }\end{array}$ & $\begin{array}{c}\text { Total } \\
\text { Radcom }\end{array}$ & $\begin{array}{c}\text { Total } \\
\text { municípios } \\
\text { com } \\
\text { Radcom }\end{array}$ & $\begin{array}{c}\text { Radcom + } \\
\text { UHEs }\end{array}$ & $\begin{array}{c}\text { Radcom } \\
+ \text { UCs }\end{array}$ & $\begin{array}{c}\text { Radcom } \\
\text { + TIs. }\end{array}$ & $\begin{array}{c}\text { Radcom } \\
\text { +UHEs } \\
\text { +UCs } \\
\text { +TIs }\end{array}$ \\
\hline AMAZONIA & $\mathbf{4 9 8}$ & $\mathbf{4 3 6}$ & $\mathbf{2 9}$ & $\mathbf{2 1 9}$ & $\mathbf{1 5 2}$ & $\mathbf{1 4}$ \\
\hline Acre & 5 & 5 & 0 & 4 & 4 & 0 \\
\hline Amapá & 17 & 14 & 2 & 15 & 4 & 1 \\
\hline Amazonas & 39 & 35 & 0 & 30 & 32 & 0 \\
\hline Pará & 118 & 95 & 7 & 54 & 34 & 5 \\
\hline Rondônia & 43 & 36 & 6 & 18 & 17 & 5 \\
\hline Roraima & 5 & 5 & 0 & 3 & 3 & 0 \\
\hline Tocantins & 69 & 68 & 3 & 25 & 4 & 0 \\
\hline Mato Grosso & 87 & 77 & 10 & 22 & 42 & 3 \\
\hline Maranháo & 115 & 101 & 1 & 48 & 12 & 0 \\
\hline
\end{tabular}

FONTES: Ministério das Comunicaçôes (jun/2015); Programa de Aceleração do Crescimento (PAC) - out. 2014; Unidades de Conservação (UCs); Ministério do Meio Ambiente (MMA); Fundação Nacional do Índio (FUNAI) - jun. 2015; Anatel - jun. 2015.

Ao cruzar todas as variáveis - Rádios Comunitárias, Usinas Hidrelétricas, Terras Indígenas e Unidades de Conservação (Tabela 1) -, sinalizam-se as localidades com maior potencial atual ou futuro de eclosáo de conflitos socioambientais pelo uso (ou não uso) dos recursos naturais. É justamente nesses territórios e sobre esses embates que a comunicação comunitária, voltada à cidadania e educação ambiental, pode fazer diferença.

Dentre os sete municípios com maior potência em termos de quantidade de unidades de variáveis entrecruzadas, o campeão é Altamira, com duas rádios comunitárias, 12 Terras Indígenas, 11 Unidades de Conservação e uma Usina Hidrelétrica em obras, Belo Monte, um dínamo de conflitos, impasses e contradiçôes há quase 40 anos. Na sequência, vêm os municípios de Itaituba (PA), Porto Velho (RO), Aripuanã (MT), Almeirim (PA), Laranjal do Jari (AP) e Nova Canaã do Norte (MT).

Chega-se, portanto, a 14 rádios comunitárias localizadas em municípios que abrigam todas as variáveis e, portanto, com maior potencial de eclosão de conflitos socioambientais. Apoiar estas emissoras com políticas públicas que lhes garantam condiçóes de autonomia e independência em seu funcionamento seria um importante passo para promover mais informação e reflexão crítica sobre a realidade local, ampliando assim as possibilidades de maior participação dos grupos locais nas decisóes que coloquem em risco a sustentabilidade de seu meio ambiente, seu bem-estar e sua qualidade de vida. 


\section{Conclusão}

As rádios comunitárias são um fenômeno de comunicação especialmente fértil e crescente em regióes periféricas do planeta. Entretanto, pelo mesmo motivo de atuarem em territórios periféricos a partir de iniciativas de grupos subalternos, as rádios comunitárias muitas vezes não conseguem impactar a agenda política ou mesmo brigar pela audiência onde propagam seus sinais, gerando em si um paradoxo: constituem-se como fenômeno crescente, relevante social e politicamente, mas desconhecido do grande público, invisível para além de suas bases ou segmentos diretamente antagônicos e não reconhecido de fato pelos tomadores de decisão. Os dados aqui apresentados, abrigados de forma dinâmica em um mapa digital, numa perspectiva socioambiental das rádios comunitárias na região amazônica, faz saltar aos olhos antes de mais nada o reconhecimento de sua existência e o papel estratégico que poderiam exercer em localidades onde os embates pelo desenvolvimento da regiáo tendem a afetar irreparavelmente o meio ambiente e o modo de vida das populaçóes locais.

Se considerarmos que existem emissoras comunitárias licenciadas em mais da metade dos municípios amazônicos (498 emissoras em 438 municípios dos 772 existentes na regiáo) e que mais da metade delas é a única emissora de rádio ou o único meio de comunicação massivo eletrônico em suas localidades - capazes, portanto, de produzir informação sobre a realidade local no meio mais popular que existe até hoje -, temos aí um cenário extremamente revelador do potencial estratégico da radiodifusão comunitária como instrumento de comunicação e educação cidadã na construção mais democrática e sustentável do desenvolvimento da Amazônia. Potencialmente.

$\mathrm{O}$ verbo no futuro do pretérito quando se fala do papel que as rádios comunitárias "poderiam exercer" indica justamente a situação condicionada e plena de incertezas da radiodifusão comunitária no país, um paradoxo de (im)possibilidades, diante da ausência de políticas de democratização da comunicação no Brasil.

\section{Referências}

ANATEL. AGÊNCIA NACIONAL DE TELECOMUNICAÇÕES. Sistema de Controle de Radiodifusão (SRD) - Disponível em http:// sistemas.anatel.gov.br/srd/ Acessado em: 15 jun. 2015.

BOURDIEU, Pierre. O Poder simbólico. Rio de Janeiro: Bertrand do Brasil, 1989. (Coleção Memória e Sociedade).

BRUNDTLAND. Relatório. Nosso Futuro Comum (1987). Disponível em: http://pt.scribd.com/doc/12906958/Relatorio-Brundtland-NossoFuturo-Comum-Em-Portugues\#scribd Acessado em: 12/5/2015

COSTA, Sergio. As cores de Ercília. Esfera pública, democracia, configuraçóes pós-nacionais. Belo Horizonte: Editora da UFMG, 2002.

FERNANDES, Marcionila; GUERRA, Lemuel (Orgs.) Contra-discurso do desenvolvimento sustentável. Belém: UNAMAZ, 2003. 
FUNAI. FUNDAÇÃO NACIONAL DO INDIO. Terras Indígenas (TI). Disponível em: http://www.funai.gov.br/index.php/indios-no-brasil/terras-indigenas Acessado em: 12.jun.2015.

GEOAMAZÔNIA. Perspectivas do meio ambiente na Amazônia (2012). PNUMA, OTCA, Universidade Del Pacífico (Peru). Disponível em: http://www.mma.gov.br/estruturas/PZEE/_arquivos/geoamaznia_28. pdf Acessado em 14/9/2014.

IBGE. Instituto Brasileiro de Geografia e Estatística. Cadastro de Municípios localizados na Amazônia Legal. 2014. Disponível em: http:// www.ibge.gov.br/home/geociencias/geografia/amazonialegal.shtm?c=2 .

IMAZON. Desmatamento em Áreas Protegidas Reduzidas na Amazônia (1995-2013). Disponível em: http://imazon.org.br/desmatamento-em-areas-protegidas-reduzidas-na-amazonia/\#ancora2. Acessado em $18 / 6 / 2015$.

INESC. Instituto Nacional de Estudos Socioeconômicos. Hidrelétricas na Amazônia: impactos em escala, planejamento em crise. Junho de 2015. Disponível em: http://amazonia.inesc.org.br/artigos/hidreletricas-na-amazonia-impactos-em-escala-planejamento-em-crise-2/ Acessado em 6/6/2015.

ISA. Instituto Socioambiental. Dossiê Belo Monte: Não há condiçóes para a Licença de Operação. Programa Xingu. ISA, Junho de 2015. Disponível em: http://www.socioambiental.org/pt-br/dossie-belo-monte Acessado em: 30/6/2015.

LEAL, Sayonara. Radiodifusão Comunitária no Brasil: desafios e perspectivas para as políticas públicas. In: RAMOS, Murilo Cesar; SANTOS, Suzy (org.). Politicas de comunicação: buscas teóricas e práticas. São Paulo: Paulus; 2007. p. 377-404.

LIMA, Venício A.; LOPES, Cristiano Aguiar. Rádios Comunitárias: coronelismo eletrônico de novo tipo (1999-2004). As autorizaçóes de emissoras como moeda de barganha politica. Disponível em: http://www.observatorio.ultimosegundo.ig.com.br/Coronelismo. Acesso em: 4/12/2007

MC. MINISTÉRIO DAS COMUNICAÇÓES. Rádios Comunitárias. Relação de Entidades Autorizadas. Espaço do radiodifusor. Disponível em: www.mc.gov.br. Acessado em 01 jul.2015.

PERUZZO, Cicilia M. K. Comunicação nos Movimentos Populares: a participaçâo na construçâo da cidadania. Petrópolis: Vozes, 1999.

Conceitos de comunicação popular, alternativa e comunitária revisitados e as reelaboraçóes no setor. ECO-Pós, v.12, n.2, maio-agosto 2009, p.46-61.

PINTO, Lúcio Flávio. De Tucurui a Belo Monte: a história avança mesmo?. Bol. Mus. Para. Emílio Goeldi. Ciênc. hum. [online]. 2012, vol.7, n.3, pp. 777-782. ISSN 1981-8122. 
MARTÍN-BARBERO, Jesús. Dos meios às mediaçôes: comunicação, cultura e hegemonia. Prefácio: Néstor García Canclini. 4. ed. Rio de Janeiro: UFRJ, 2006.

SACHS, Ignacy. Desenvolvimento: includente, sustentável, sustentado. Rio de Janeiro: Garamond, 2004

SNUC/MME. SISTEMA NACIONAL DE UNIDADES DE CONSERVAÇÃO/MINISTÉRIO DO MEIO AMBIENTE.

STEINBRENNER, Rosane Maria Albino. Rádios Comunitárias na Transamazônica: Desafios da comunicação comunitária em regióes periféricas. 386 f. Tese (Doutorado em Desenvolvimento Sustentável do Trópico Úmido). Belém: 2011, UFPA.

VEIGA. José Eli da. Desenvolvimento sustentável: o desafio do século XXI. Rio de Janeiro: Garamond, 2005.

_____. A Emergência Socioambiental. São Paulo: Editora Senac, 2007.

VERÍSSIMO, Adalberto et al (Orgs.). Áreas Protegidas na Amazônia Brasileira: avanços e desafios. Belém: IMAZON; São Paulo: Instituto Socioambiental, 2011.

\section{Notas}

1. Trabalho apresentado no GT Redes Sociais e Políticas Públicas durante o Simpósio Brasileiro de Desenvolvimento Territorial Sustentável, UFPR Litoral, 29 e 30 de outubro de 2015.

2. Projeto financiado pelo Conselho Nacional de Pesquisa e Desenvolvimento Científico (CNPq), por meio do Edital MCTI/CNPq/MEC/CAPES N.18/2012 Ciências Humanas, Sociais e Sociais Aplicadas.

3. O mapa digital foi desenvolvido em parceria com a Produtora Colaborativa - Produtora Cultural de Projetos e Eventos de Comunicação Comunitária, Cultura Digital, Economia Solidária, Software Livre e Desenvolvimento Local, que atua na Amazônia. Endereço: www.produtoracolaborativa.com.br.

4. Dados apontam que, entre 2003 e 2006, a criação de 485 mil quilômetros quadrados de Áreas Protegidas na Amazônia, que incluem UC e TI, teria contribuído para reduzir em 37\% a taxa de desmatamento no período (SOARES-FILHO et al., 2010, apud IMAZON, s/d). Por outro lado, entre agosto de 2012 e julho de 2014, $10 \%$ dos 1.531 .000 hectares desmatados na Amazônia pertenciam a 160 unidades de conservação.

5. Ver "Obra do lago de Belo Monte espalha caos". O Estado de S. Paulo, 27/6/2015 (19h48). Disponível em: http://economia.estadao.com.br/noticias/ geral,novanoticia,1714861. Ver também: "Belo Monte, empreiteiras e espelhinhos", Eliane Brum, Opinião, El País Brasil, 6/7/2015, 12h49. Disponível em: http://brasil. elpais.com/brasil/2015/07/06/opinion/1436195768_857181.html.

6. A tabela traz os últimos dados gerais sobre a radiodifusão no país divulgados pelo governo, em maio de 2014 (Planilha com dados numéricos de emissoras em todo o país - http://www2.mcti.gov.br/index.php/dados-do-setor). O atual Ministério, da Ciência, Tecnologia, Inovações e Comunicações (MCTIC) não divulgou nenhum 
painel com dados gerais da radiodifusão sonora no país e, ao buscar atualizar os dados para este artigo, constatou-se que o atual governo, ao contrário, tornou ainda mais difícil e burocrático o acesso aos dados também por setor.

7. Segundo dados do Ministério das Comunicaçôes de setembro de 2014, a radiodifusão sonora comercial na Região Norte, mais os estados do Mato Grosso e Maranhão, totalizavam 668 emissoras de rádio (386 FM, 241 AM, 03 OC e 38 OT). Disponível em: http://www.comunicacoes.gov.br/espaco-do-radiodifusor/ radiodifusao-comercial. Acessado em: 20/5/2015.

8. A periferia, segundo Santos (2007), vem a ser, o lugar onde se é duplamente penalizado: pelos processos de segmentaçáo (de trabalho e classe social) característicos do capitalismo e pelo modo territorial de distinção e desigualdades. Como vivemos num mundo onde o valor do indivíduo depende, em larga escala, não apenas do que se tem, mas também do lugar onde se está, morar na periferia é condenar-se duas vezes à pobreza (SANTOS, 2001, p. 139).

9. De acordo com Habermas (1996), é na esfera pública, como espaço público politicamente influente, que os diferentes grupos constitutivos de uma sociedade múltipla e diversa partilham argumentos, formulam consensos e constroem problemas e soluçôes comuns. A esfera pública conforma assim o "contexto público comunicativo, no qual os membros de uma comunidade política plural constituem as condiçôes de possibilidade da convivência e da tolerância mútua, além dos acordos em torno das regras que devem reger a vida comum" (HABERMAS, 1996, p. 156 apud COSTA, 2002, p. 27).

10. Para entender a diferença entre os números, é importante destacar que um mesmo município abriga muitas vezes mais de uma Terra Indígena ou Unidade de Conservação em seu território e que cerca de $10 \%$ dos municípios possuem mais de uma rádio licenciada.

11. Ferreira Gomes (AP); Jirau (RO); Santo Antônio (RO); Santo Antônio Jari (AP e PA).

12. Dardanelos (MT); Estreito ( MA e TO).

13. Belo Monte (PA); Colíder (MT); São Manoel (MT e PA); Sinop (MT); Teles Pires (MT e PA).

14. Jatobá (PA); São Luiz do Tapajós (PA). 